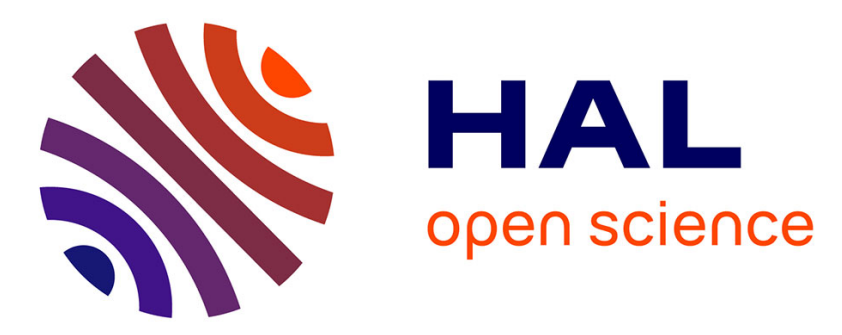

\title{
Finite element modelling of an energy-storing prosthetic foot during the stance phase of transtibial amputee gait
}

Xavier Bonnet, Helene Pillet, Pascale Fode, Francois Lavaste, Wafa Skalli

\section{To cite this version:}

Xavier Bonnet, Helene Pillet, Pascale Fode, Francois Lavaste, Wafa Skalli. Finite element modelling of an energy-storing prosthetic foot during the stance phase of transtibial amputee gait. Journal of Engineering in Medicine, 2012, 226 (1), pp.70-75. 10.1177/0954411911429534 . hal-01083618

\section{HAL Id: hal-01083618 https://hal.science/hal-01083618}

Submitted on 17 Nov 2014

HAL is a multi-disciplinary open access archive for the deposit and dissemination of scientific research documents, whether they are published or not. The documents may come from teaching and research institutions in France or abroad, or from public or private research centers.
L'archive ouverte pluridisciplinaire HAL, est destinée au dépôt et à la diffusion de documents scientifiques de niveau recherche, publiés ou non, émanant des établissements d'enseignement et de recherche français ou étrangers, des laboratoires publics ou privés. 


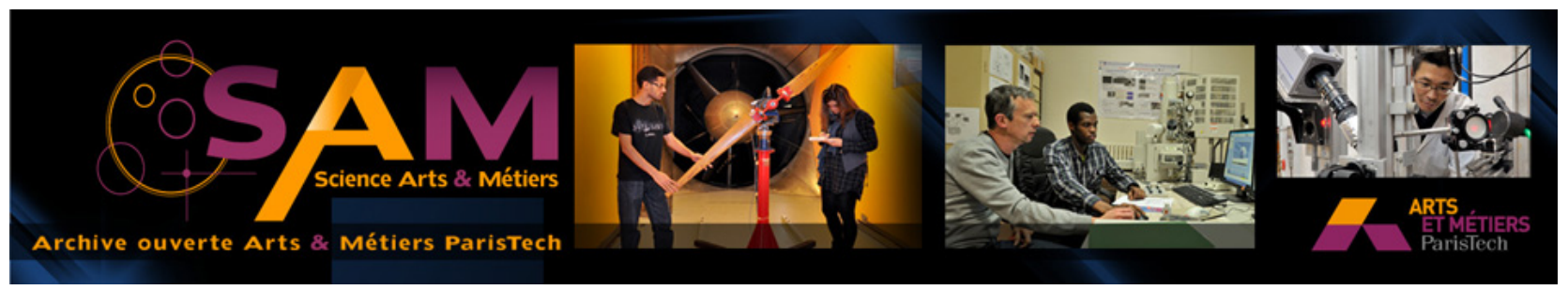

\section{Science Arts \& Métiers (SAM)}

is an open access repository that collects the work of Arts et Métiers ParisTech researchers and makes it freely available over the web where possible.

This is an author-deposited version published in: http://sam.ensam.eu

Handle ID: .http://hdl.handle.net/10985/8915

\section{To cite this version :}

Xavier BONNET, Helene PILLET, Pascale FODE, Francois LAVASTE, Wafa SKALLI - Finite element modelling of an energy-storing prosthetic foot during the stance phase of transtibial amputee gait - Journal of Engineering in Medicine - Vol. 226, n¹, p.70-75 - 2012 


\title{
Finite element modelling of an energy-storing prosthetic foot during the stance phase of transtibial amputee gait
}

\author{
Xavier Bonnet', Hélenè Pillet', Pascale Fodé ${ }^{2}$, Francois Lavaste ${ }^{1,2}$ and \\ Wafa Skalli'
}

\begin{abstract}
Energy-storing prosthetic feet are designed to store energy during mid-stance motion and to recover it during latestance motion. Gait analysis is the most commonly used method to characterize prosthetic foot behaviour during walking. In using this method, however, the foot is generally modelled as a rigid body. Therefore, it does not take into account the ability of the foot to deform. However, the way this deformation occurs is a key parameter of various foot properties under gait conditions. The purpose of this study is to combine finite element modelling and gait analysis in order to calculate the strain, stress and energy stored in the foot along the stance phase for self-selected and fast walking speeds. A finite element model, validated using mechanical testing, is used with boundary conditions collected experimentally from the gait analysis of a single transtibial amputee. The stress, strain and energy stored in the foot are assessed throughout the stance phase for two walking speed conditions: a self-selected walking speed (SSWS), and a fast walking speed (FWS). The first maximum in the strain energy occurs during heel loading and reaches $3 \mathrm{~J}$ for SSWS and 7J for FWS at the end of the first double support phase. The second maximum appears at the end of the single support phase, reaching I5 J for SSWS and 18 J for FWS. Finite element modelling combined with gait analysis allows the calculation of parameters that are not obtainable using gait analysis alone. This modelling can be used in the process of prosthetic feet design to assess the behaviour of a prosthetic foot under specific gait conditions.
\end{abstract}

\section{Keywords}

Biomechanics, gait analysis, strain energy

\section{Introduction}

In transtibial amputee gait, it has been shown that more energy is required while walking at lower speeds. ${ }^{1}$ Energystoring prosthetic feet have been designed to better reproduce the behaviour of the physiologic foot. For instance, the use of composites creates a reduction in mass, an increase in gait symmetry and an improvement in gait efficiency. The evaluation of these feet requires the study of both mechanical and functional behaviours. Mechanical behaviour has been explored by Van Jaarsveld et al. ${ }^{2}$ and Postema et al. ${ }^{3}$ They measured the stiffness and hysteresis of several prosthetic feet at different ankle positions and showed a wide range of mechanical properties.

The functional behaviour of prosthetic feet has commonly been evaluated through gait analysis. One of the expected functions of a prosthetic foot is to restore the mobility of the ankle and particularly its propulsive role at the end of the stance. Most gait analysis studies have considered the prosthetic foot as being a single rigid body ${ }^{4}$ that is articulated with the prosthetic shank. However, the mobility of the ankle has rarely been obtained by using a mechanical link between the foot and the tibia. Instead, it is accomplished by taking advantage of the elastic properties of flexible materials. Thus, gait analysis has not been adapted to allow it to

\footnotetext{
'Arts et Metiers ParisTech, Laboratoire de Biomecanique, I5I bd de I'hôpital 75013 Paris, France

${ }^{2}$ Institution Nationale des Invalides, Centre d'Etudes et de Recherche sur l'Appareillage des Handicapés, F-57|40 Woippy, France
}

\section{Corresponding author:}

Hélène Pillet, Arts et Metiers ParisTech, Laboratoire de Biomecanique, I5I bd de l'hopital 750 I3 Paris, France

Email: helene.pillet@ensam.eu 
represent the dynamic elastic response behaviour of feet during the stance phase of motion.

Finite element modelling (FEM) allows the analysis of the responses of a deformable structure under known boundary conditions. FEM has been widely used to assess the stress between the residual limb and the socket ${ }^{5-7}$ Few studies, however, have focused on the modelling of a prosthetic foot during the stance phase of motion. Indeed, the creation of a FEM model requires information on the geometry, material properties and boundary conditions of the structure. The assessment of physiological boundary conditions, although difficult to obtain, is critical for the reliability of the modelling studies. Allard et al. ${ }^{8}$ built a FEM model in order to calculate the strain and energy stored in the foot during the push-off phase of movement. Saunders et al. ${ }^{9}$ measured the forces and contact surface between the foot and the floor at heel strike, at middle stance and at push-off in the movement cycle of a below-knee amputee. They modelled a solid ankle cushion heel foot and calculated the stress applied to the foot. Lee and $\mathrm{Zhang}^{10}$ built a model in order to optimize the design of a monolimb under the boundary conditions imposed by the ISO norm 10328 (Structural testing of lower-limb prostheses). The results of these studies are limited in their applicability since the real boundary conditions during the gait were not taken into account by Lee and Zhang, ${ }^{10}$ and models devised by Allard et al. ${ }^{8}$ and Saunders et al. ${ }^{9}$ focused only on specific kinetic events in the gait cycle.

Therefore, there is a need to collect real boundary conditions in order to simulate the whole stance phase of the gait. The aims of this study were to:

(a) build and validate a finite element model of a prosthetic foot;

(b) collect experimental boundary conditions for selfselected walking speed (SSWS) and fast walking speed (FWS);

(c) calculate stress, strain and strain energy of the prosthetic foot for the whole stance phase using those boundary conditions.

\section{Methods}

\section{Prosthetic foot description and finite element model}

The considered prosthetic foot consisted of a J-shape linked with a split sole (Figure 1). The mobility of the tibia relative to the foot was obtained by the J-shape deformation. Geometry and material properties were provided by the manufacturer. The geometry of the foot was created with Solidworks ${ }^{\circledR}$ (Concord, Massachusetts, USA). Fillets, drillings and screws were not taken into account and also the foot shell was not considered in this model. The Solidworks model was imported into Ansys ${ }^{\circledR}$ (Canonsburg, Pennsylvania, USA) and meshed with brick-shaped elements (threedimensional (3D) 20-node structural solid). Links between the different volumes were modelled with surface-to-surface contact elements (3D four-node surface-to-surface contact), thus avoiding penetration. Sliding was not permitted. Material properties were linear and isotropic. The Young's modulus and Poisson's ratio of the foot that was made of carbon and glass fibre were $35,000 \mathrm{MPa}$ and 0.3 , respectively. The model included 9006 nodes and 4574 elements.

\section{Mechanical testing and finite element model validation}

Currently, the structural test specifications of lower-limb prostheses are specified in ISO10328. Mechanical tests based on ISO norm 10328 were performed on the prosthetic foot using an Instron (Elancourt, France) testing machine. The fixation system (Figure 1) allowed an orientation of $20^{\circ}$ of plantar flexion simulating push-off and $15^{\circ}$ in dorsal flexion extension simulating heel loading. A constant loading rate of $250 \mathrm{~N} / \mathrm{s}$ was applied up to $1300 \mathrm{~N}$ of vertical compression with a loading plate free to move in horizontal translation. The structural test specifications of the ISO 10328 were reproduced with the finite element model. The loading plate was assumed to be rigid. Contact elements were considered at the interface between the foot and the plate. The plate was free to move in the horizontal plane. A vertical displacement was applied progressively until the reaction forces reached $1200 \mathrm{~N}$. Load-displacement curves obtained with the mechanical test on the heel and on the forefoot were compared with those obtained with the finite element model. Linear stiffness was evaluated from both experimental and finite element model curves.

\section{Boundary conditions collected during gait analysis}

In the present study, only the collection of boundary conditions was provided by gait analysis. This gait analysis was performed within a clinical follow up of a 42-year-old below-knee amputee (mass: $85 \mathrm{~kg}$ ) using the routine protocol described previously by Pillet et al. ${ }^{11}$ The patient was amputated more than 10 years ago and has been wearing the foot for more than 2 years. The residual limb was about one-third the length of the intact limb. The patient gave his informed consent for use of the boundary conditions collected

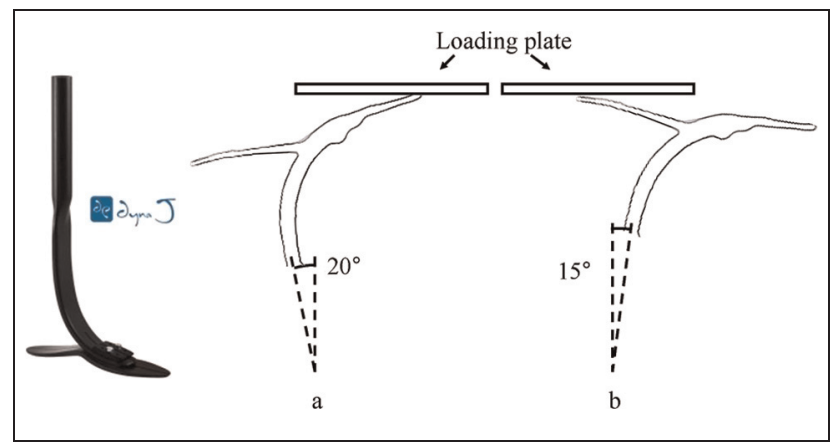

Figure I. The modelled DynaJ (Proteor, France) prosthetic foot and its mechanical testing (a) forefoot loading and (b) heel loading. 
during the gait exam. The use of these data was made in accordance with both participating institutions and in accordance with the Declaration of Helsinki which defines ethical principles for medical research involving human subjects.

The amputation was the result of trauma. The subject wore his own prosthesis during the experiment. Measurements were performed at the patient's SSWS (mean: $0.99 \mathrm{~m} / \mathrm{s}$ - std: $0.04 \mathrm{~m} / \mathrm{s}$ ) and at the patient's FWS (mean: $1.59 \mathrm{~m} / \mathrm{s}$ - std: $0.17 \mathrm{~m} / \mathrm{s}$ ). The patient was an athlete, which explained the relatively high speed he could reach compared to published values of velocity for transtibial gait. Ten trials were performed for each speed. Optoelectronic measurements were performed with a MX8 Vicon $^{\circledR}$ (Hauppauge, New York, USA) system composed of eight cameras. Ground reaction forces were acquired with two $\mathrm{Amti}^{\circledR}$ (Watertown, Massachusetts, USA) force plates at $60 \mathrm{~Hz}$. Gait trials were collected on a $10 \mathrm{~m}$ walkway.

\section{Definition of the boundary conditions used in the FEM}

The model was built in a specific coordinate system (model's coordinate system (MCS)) defined as follows:

- $y$-axis: axis of the pylon;

- $\quad x$-axis: antero-posterior axis;

- $z$-axis: cross-product of $x$-axis and $y$-axis.

A technical cluster of four markers was attached to the socket. The cluster's coordinate system (CCS) was defined using the $3 \mathrm{D}$ coordinates of the markers. A static acquisition was performed and two photographs were taken from the front and lateral sides simultaneously. Four markers were added on the ground. The positions of the markers in the photographs were registered by simultaneous collection using the motion capture system. These spatial coordinates were subsequently used for calibration of the image using a direct linear transformation (DLT) algorithm. The digital model of the prosthetic foot was then projected onto the calibrated photographs and manual rigid displacement was applied to the model in order that the model's geometry corresponded to the photograph's contour (Figure 2). This static process allowed calculation of the transformation matrix between the CCS and the MCS (MCCS-> MCS - time-invariant).

During gait acquisitions, the transformation matrix between the Vicon's coordinate system (VCS) and the MCS (MVCS->MCS) was calculated via the CCS attached to the socket. The time-invariant CCS was directly computed from the 3D positions of the markers for each acquisition (Figure 3).

Ground reaction forces were measured in VCS and then expressed in the MCS using the matrix MVCS$>$ MCS for each trial using Matlab ${ }^{\circledR}$ software (Natick, Massachusetts, USA). The vertical and anteroposterior

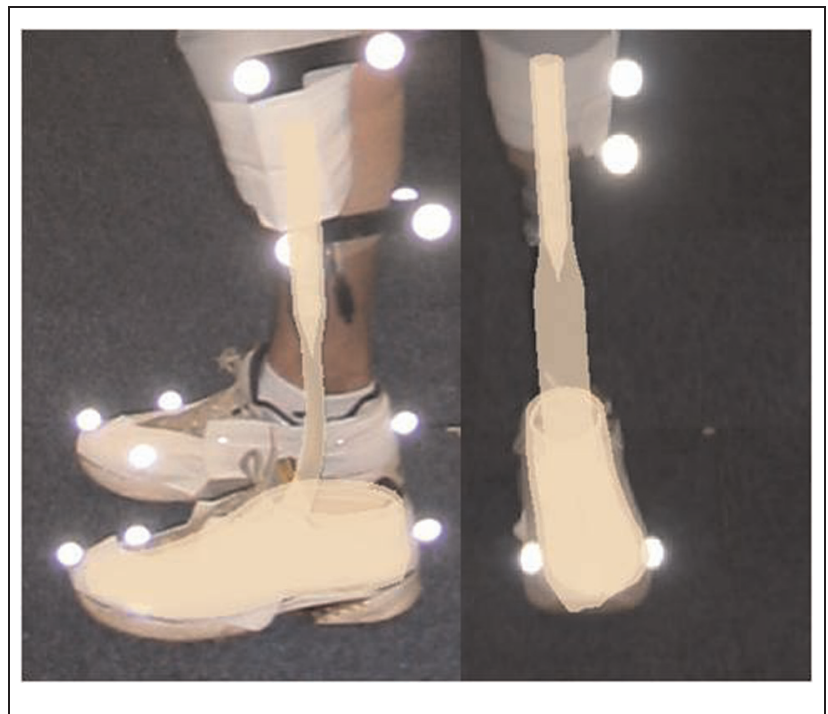

Figure 2. Registration of the digital model of the prosthetic foot on the calibrated photographs.

components of the force and points of application were averaged and normalized by body mass according to the stance phase. These forces could then be considered as external forces for the finite element model.

\section{Simulation of the stance phase}

The socket-foot link was fixed, and then the ground reaction forces calculated in the MCS were applied in the finite element model. The mediolateral component of the forces was neglected. Large displacements were considered. For each step, forces were applied to the deformed shape (calculated at the prior step) using the nearest node of the centre of pressure measured experimentally. Strain, stress and deformed shape were calculated in the MCS and expressed in VCS. Simulation allowed the computation of the total strain energy in the model. This energy was normalized by the percentage of the stance phase for SSWS and FWS.

\section{Results}

The obtained load-displacement curves showed a linear part in the range of displacement from 0 to $45 \mathrm{~mm}$ for the forefoot loading case and from 0 to $10 \mathrm{~mm}$ for the heel loading case (Figure 4). After this linear part, a non-linearity appeared which was caused by the modification of the contact between the foot and the loading plate. The linear stiffness values calculated for both experimental and finite element model curves are listed in Table 1.

The model matched the results obtained in the mechanical test for the forefoot loading case, but it was less applicable to the heel loading case. Stiffness modification due to the contact was more sensitive in the heel loading case. The trajectories of the centre of pressure in the MCS were similar for both speeds, except for heel contact. 

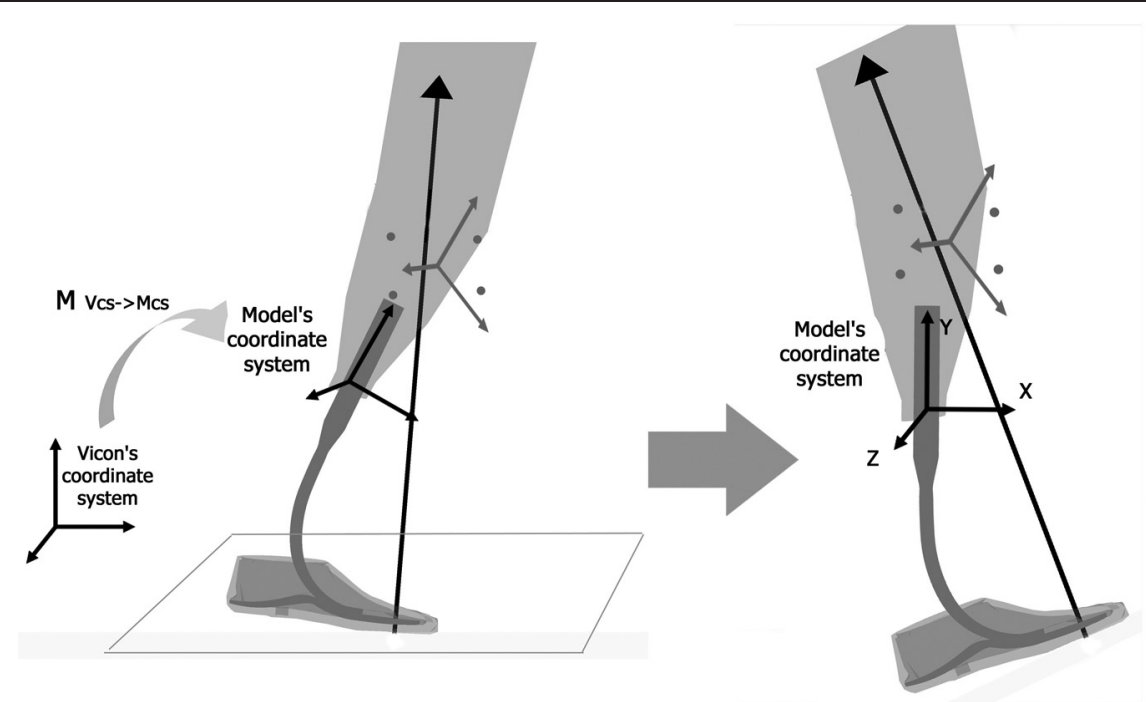

Figure 3. Definition of the MCS and transformation of the boundary conditions used in the FEM.

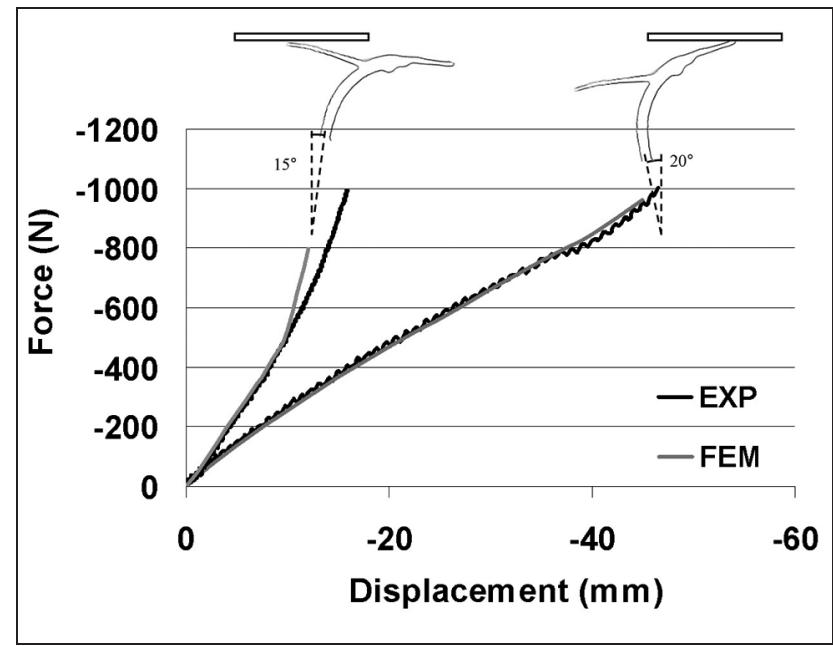

Figure 4. Validation of the finite element model: load-displacement curves are presented for the experimental test (black line) and FEM (grey line) for heel loading (on the left) and for forefoot loading (on the right) based on the ISO norm boundary condition.

The amplitude of the vertical component presented two peaks for both the SSWS and the FWS. The first peak reached a value of $850 \mathrm{~N}$ for SSWS and $1000 \mathrm{~N}$ for FWS at heel contact. During mid-stance, the vertical effort decreased to $750 \mathrm{~N}$ for SSWS and $500 \mathrm{~N}$ for FWS. The amplitude at push-off reached $800 \mathrm{~N}$ for both speeds.

The total strain energy in the foot is shown as a function of thee stance phase in Figure 5. Two maxima can be observed. The first maximum occurs during heel loading and reaches $3 \mathrm{~J}$ for SSWS and $7 \mathrm{~J}$ for FWS at the end of the first double support phase. Strain appears principally in the heel and in the J-shape. Between the two maxima, the strain energy decreases and approaches zero as the $\mathrm{J}$-shape returns to its
Table I. Comparison of linear stiffness.

\begin{tabular}{lrc}
\hline Stiffness & Heel test & Forefoot test \\
\hline Experimental $(\mathrm{N} / \mathrm{mm})$ & 58.9 & 21.5 \\
Finite element model $(\mathrm{N} / \mathrm{mm})$ & 61.7 & 22.7 \\
Error prediction on stiffness (\%) & 4.8 & 5.6 \\
\hline
\end{tabular}

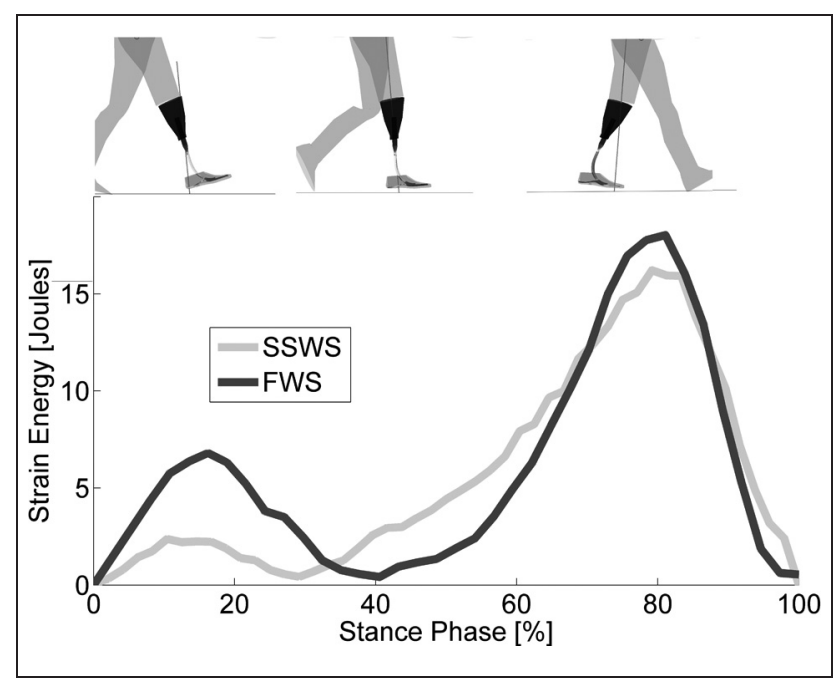

Figure 5. Strain energy stored in the foot during the stance phase.

original shape at $30 \%$ of the stance phase for SSWS and $40 \%$ of the stance phase for FWS. During the rest of the single support phase, the deformation of the J-shape allows the amputee to keep the foot flat on the floor and to flex the socket over the floor. The second maximum appears at the end of the single support phase reaching $15 \mathrm{~J}$ for SSWS and $18 \mathrm{~J}$ for FWS, respectively. This energy decreases to zero during the second double support. 


\section{Discussion}

The present work proposes an original method to assess the physiological boundary conditions of gait and to apply them to a finite element model of a prosthetic foot. The use of the model allows the calculation of stress, strain and strain energy of the prosthetic foot for the whole stance phase using the boundary conditions at two walking speed conditions for a single patient.

The model was first validated by comparing its behaviour to that of the real prosthetic foot under the conditions defined by the norm on structural testing of lower-limb prostheses. For heel and forefoot loading, the finite element model was validated from 0 to $850 \mathrm{~N}$ with an error less than $6 \%$ of the vertical stiffness. During mechanical testing, the energy lost between the loading and the unloading was lower than $10 \%$ thus validating the assessment of the linear elastic behaviour of the material and the simplifications adopted for the foot's geometry (drillings and fillets).

Mechanical tests allowed the assessment of the stiffness and the stored energy in the foot under specific boundary conditions. Van Jaarsveld et al. ${ }^{2}$ proposed a specific set up that allowed the foot to be loaded in 66 positions between heel strike and toe-off. Such experiments are time-consuming, whereas an accurate finite element model is an effective tool to optimize foot design after experimental validation.

Data fusion between the optoelectronic measurement, ground reaction forces and finite element model was obtained by an original method consisting of the use of two photographs. This method allowed the determination of the nodes on which the boundary conditions are applied. The boundary conditions applied to the model, principally during heel loading, depended on walking speed. The trajectory of the centre of the pressure in the foot's coordinate system was not affected by the walking speed.

The conventional calculation of energy storage in prosthetic feet by inverse dynamics analysis assumes motion between two rigid bodies and necessitates the location of the centre of rotation between the pylon and the foot. ${ }^{12}$ Results using such methods depend on the model definition and Geil et al. ${ }^{13}$ reported that conventional inverse dynamics methods may have limitations in the analysis of certain prosthetic feet. The definition of two rigid bodies and a centre of rotation are difficult for energy-storing feet, especially in the case considered in this paper where the whole keel deforms during stance and would induce errors in the moment computation.

The method proposed in the present paper has some limitations. It necessitates a supplementary static acquisition of the prosthesis in order to realize registration of the digital model in the cluster frame. The data fusion phase, although relatively fast (the manual part of the work takes about $5 \mathrm{~min}$ ), necessitates a trained operator and cannot be done in current clinical routines. Finally, foot cover and shoe effect were not taken into account, by the hypothesis that their influence can be neglected, as they do not store energy during gait. The effect of the alignment was not investigated in the present study although it has been shown to be an essential parameter of transtibial gait. ${ }^{14}$ Data provided by the model, however, are obviously complementary to data obtained from the classical use of inverse dynamic calculations from gait analysis used to understand the behaviour of the foot during stance.

In regards to strain energy, Allard et al. ${ }^{8}$ calculated the strain energy stored in push-off under $700 \mathrm{~N}$ of vertical force applied to the extremity of the forefoot using FEM (17.4J). The energy measured in the present study ranges from 3 to $7 \mathrm{~J}$ during heel loading and from 15 to $20 \mathrm{~J}$ at push-off. This energy is comparable in size to that found by Allard et al. ${ }^{8}$ for the push-off phase. The strain energy stored at heel loading was recovered during the first part of the single support. The energy stored during the second part of the single support, when the socket flexed over the ground, was recovered during the second double support. The whole stance phase can thus be considered to be essential since it is apparent that the energy returned during the push-off was stored only during the second part of the single support phase and not during heel loading.

The results depend on both the design of the foot and the boundary conditions applied by the user. The results in this study were limited to one amputee with one foot. Besides, the patient who participated was an athlete and was able to walk at relatively high speeds. However, the aim of this study was to propose a methodology to fuse gait analysis data with FEM and not to give reference data of transtibial gait. Moreover, in this study, attention was focused on the strain energy stored in the foot during the stance phase, but this analysis did not reveal if this energy benefits the user and how he or she interacts with the prosthetic foot. Nevertheless, quantifying the deformation of the foot is useful to optimize foot design in order to mimic the physiological foot. Indeed, the energy stored during deformation aims to compensate for the loss of muscles due to the amputation.

\section{Conclusions}

FEM combined with gait analysis allows for the calculation of parameters that are not obtainable through kinematic analysis. This modelling is particularly useful to calculate deformation energy of the foot throughout the entire stance phase. Therefore, the behaviour of a prosthetic foot can be assessed during the process of prosthetic feet design.

\section{Funding}

This research received no specific grant from any funding agency in the public, commercial or not-for-profit sectors. 


\section{Acknowledgements}

The authors would like to thank the patient in this study, the CERAH (Centre d'Etudes et de Recherche sur l'Appareillage des Handicapés, France) and Proteor, which supported this study.

\section{References}

1. Waters RL, Perry J, Antonelli D and Hislop H. Energy cost of walking of amputees: the influence of level of amputation. J Bone Joint Surg Am 1976; 58(1): 42-46.

2. Van Jaarsveld HW, Grootenboer HJ, De Vries J and Koopman HF. Stiffness and hysteresis properties of some prosthetic feet. Prosthet Orthot Int 1990; 14(3): 117-124.

3. Postema K, Hermens HJ, De Vries J, Koopman HF and Eisma WH. Energy storage and release of prosthetic feet. Part 1: biomechanical analysis related to user benefits. Prosthet Orthot Int 1997; 21(1):17-27.

4. Goujon H, Bonnet X, Sautreuil P, et al. A functional evaluation of prosthetic foot kinematics during lowerlimb amputee gait. Prosthet Orthot Int 2006; 30(2): 213-223.

5. Faustini MC, Neptune RR and Crawford RH. The quasi-static response of compliant prosthetic sockets for transtibial amputees using finite element methods. Med Engng Phys 2006; 28(2):114-121.

6. Zachariah SG and Sanders JE. Interface mechanics in lower-limb external prosthetics: a review of finite element models. IEEE Trans Rehab Engng 1996; 4(4): 288-302.
7. Zhang $\mathrm{M}$ and Roberts C. Comparison of computational analysis with clinical measurement of stresses on belowknee residual limb in a prosthetic socket. Med Engng Phys 2000; 22(9): 607-612.

8. Allard P, Trudeau F, Prince F, et al. Modelling and gait evaluation of asymmetrical-keel foot prosthesis. Med Biol Engng Comput 1995; 33(1): 2-7.

9. Saunders MM, Schwentker EP, Kay DB, et al. Finite element analysis as a tool for parametric prosthetic foot design and evaluation. Technique development in the solid ankle cushioned heel (SACH) foot. Comput Methods Biomech Biomed Engng 2003; 6(1): 75-87.

10. Lee WC and Zhang M. Design of monolimb using finite element modelling and statistics-based Taguchi method. Clin Biomech (Bristol, Avon) 2005; 20(7): 759-766.

11. Pillet H, Bonnet X, Lavaste F and Skalli W. Evaluation of force plate-less estimation of the trajectory of the centre of pressure during gait. Comparison of two anthropometric models. Gait Posture 2010; 31(2), 147-152.

12. Hansen AH, Miff SC, Childress DS, et al. Net external energy of the biologic and prosthetic ankle during gait initiation. Gait Posture 2010; 31: 13-17.

13. Geil MD, Parnianpour M, Quesada P, et al. Comparison of methods for the calculation of energy storage and return in a dynamic elastic response prosthesis. $J$ Biomech 2000; 33(12): 1745-1750.

14. Schmalz T, Blumentritt S and Jarasch R. Energy expenditure and biomechanical characteristics of lower limb amputee gait: the influence of prosthetic alignment and different prosthetic components. Gait Posture 2002; 16: 255-263. 